\title{
Synthesis and Characterization of $(\mathrm{Cr}, \mathrm{Fe})$-doped $\mathrm{Y}_{2} \mathrm{O}_{3}-\mathrm{Al}_{2} \mathrm{O}_{3}$ Red Pigments \\ Kyung-Hyun Shin ${ }^{\dagger}$ and Byung-Ha Lee
}

Department of Materials Science \& Engineering, Myongji University, Yongin 449-728, Korea

(Received January 30, 2009; Revised April 27, 2009; Accepted June 15, 2009)

\author{
$(\mathrm{Cr}, \mathrm{Fe})$-doped $\mathrm{Y}_{2} \mathrm{O}_{3}-\mathrm{Al}_{2} \mathrm{O}_{3}$ 계 붉은 안료의 합성과 특성 \\ 신경현 ${ }^{\dagger}$ 이병하 \\ 명지대학교 공과대학 신소재공학과 \\ (2009년 1월 30일 접수 ; 2009년 4월 27일 수정 ; 2009년 6월 15일 승인)
}

\begin{abstract}
Perovskite codoped with chromium and iron have been studied. Samples with $\mathrm{YAl}_{0.96}\left(\mathrm{Cr}_{0.04-\mathrm{x}} \mathrm{Fe}_{\mathrm{x}}\right) \mathrm{O}_{3}(\mathrm{x}=0.01,0.02,0.03,0.04)$ were prepared by solid state reaction at $1450^{\circ} \mathrm{C}$ for $6 \mathrm{~h}$ and were characterized by XRD, FT-IR, Raman spectroscopy, SEM and UV-vis spectrophotometer. The color of the synthesized pigments were from red to dark brown(in bulk). Up to $0.02 \mathrm{~mole}^{\mathrm{Fe}} \mathrm{O}_{3}$ for substituting $\mathrm{Cr}_{2} \mathrm{O}_{3}$ development of color in lime-glaze gives good red color but as increasing amount of $\mathrm{Fe}_{2} \mathrm{O}_{3}$ and decreasing $\mathrm{Cr}_{2} \mathrm{O}_{3}$ proportionally produce from brownish red to brown. Increasing $\mathrm{Fe}_{2} \mathrm{O}_{3}$ amount lead to weaken crystal field relatively due to have smaller ionic radius than $\mathrm{Cr}_{2} \mathrm{O}_{3}$ ionic one. The UV-vis peaks were shifted to lower wavelength.
\end{abstract}

Key words : Codoped, Pigment, Red color, Crystal field

\section{1. 서 론}

열적 안정성과 화학적 안정성 및 환경적인 안전문제 까 지를 고려한 새로운 붉은 안료의 개발은 세라믹 산업에서 간절한 문제이다. 붉은 안료를 얻을 수 있는 방법에는 알 려져 있듯이 말라야트 $\left(\mathrm{CaSnSiO}_{5}: \mathrm{Cr}\right)$, 코런덤 $\left(\mathrm{Al}_{2} \mathrm{O}_{3}: \mathrm{Cr}\right.$ or $\mathrm{Mn})$, 철 포접 지르콘 $\left(\mathrm{ZrSiO}_{4}: \mathrm{Fe}\right)$ 및 카드뮴과 세렌이 포접 된 지르콘 $\left(\mathrm{ZrSiO}_{4}: \mathrm{Cd}, \mathrm{Se}\right)$ 등 여러 방법이 있다. 그러나 이 들 안료의 색상은 카드뮴과 세렌이 들어간 안료를 제외하 고는 순수한 붉은 색과는 거리가 있다. 또한 greenokite라 불리는 카드뮴과 세렌이 포접된 안료의 경우는 강한 붉 은 색을 발색하지만 카드뮴과 세렌의 독성 때문에 인체 와 환경에 미치는 영향으로 생산과정에서 법적인 제한을 받아 이들을 대체할 안료생산에 관한 연구들이 행해지고 있다. 특히 세계적으로 대두되고 있는 환경문제와 맞물려 이들 독성 물질의 사용은 점점 설자리를 잃고 있다. 붉은 색 발색의 발색단으로 사용되고 있는 크롬(III)화합물은 본래부터 독성을 보여주지 않지만 사용은 확인된 발암 물 질인 $\mathrm{Cr}(\mathrm{VI})$ 으로의 산화 가능성 때문에 유해폐기물과 관 련하여 관리되고 있다. ${ }^{1)}$

\footnotetext{
${ }^{\dagger}$ Corresponding author: Kyung-Hyun Shin

E-mail : shinsaem@naver.com

Tel : +82-31-330-6461 Fax : +82-31-330-6457
}

본 논문에서는 앞서 보고한 논문 ${ }^{2}$ 에서 붉은 발색에 대 한 최적의 크롬 사용량에서 환경적인 문제를 야기할 수 있는 크롬의 양을 줄이고도 붉은 발색을 할 수 있는 안 료를 개발하기 위해 발색제로 크롬과 마찬가지로 널리 쓰 이는 철로 크롬을 얼마나 대체하여 붉은 안료를 합성할 수 있는지를 실험하였다.

\section{2. 실험방법}

\section{1. 안료의 합성}

고온 도자기용 안료를 합성하기 위해 $\mathrm{Y}_{2} \mathrm{O}_{3}$ (France, industrial grade), $\mathrm{Al}(\mathrm{OH})_{3}$ (Junsei, Japan, chemical pure), $\mathrm{Cr}_{2} \mathrm{O}_{3}$ (Duksan, Korea, $99 \%$ ), $\mathrm{Fe}_{2} \mathrm{O}_{3}$ (Hanil Chem., Korea, first grade), $\mathrm{FeCl}_{3} \cdot \mathrm{H}_{2} \mathrm{O}$ (Duksan, Korea, extra pure), $\mathrm{CrCl}_{3} \cdot 6 \mathrm{H}_{2} \mathrm{O}$ (Duksan, Korea, extra pure), $\mathrm{NaF}$ (Duksan, Korea, practical grade), $\mathrm{MgF}_{2}$ (Junsei, Japan, chemical pure), $\mathrm{Li}_{2} \mathrm{CO}_{3}(\mathrm{Kanto}$, Japan, Cica-Reagent)를 출발 원료로 사용하였다.

실험에 사용된 조합은 보고된 실험에에서 합성안료의 색 상과 발색이 가장 좋았던 $1450^{\circ} \mathrm{C}$ 의 $\mathrm{YAl}_{0.96} \mathrm{Cr}_{0.04} \mathrm{O}_{3}$ 조합 을 선택하여 실험의 출발로 하였다. 크롬이 $0.04 \mathrm{~mole}$ 사 용되었던 조합의 발색제 크롬을 $0.01 \mathrm{~mole}$ 에서 $0.04 \mathrm{~mole}$ 까지 산화철로 대체하여 붉은 안료 합성 실험을 하였다 (Table 1). 페로브스카이트 구조를 갖는 안료를 합성하기 
Table 1. Compositions of Samples

\begin{tabular}{ll}
\hline \multicolumn{1}{c}{ Sample No. } & \multicolumn{1}{c}{ Composition } \\
\hline $\mathrm{Cr} 4(\mathrm{CrCl})$ & $\mathrm{YAl}_{0.96} \mathrm{Cr}_{0.04} \mathrm{O}_{3}$ \\
$\mathrm{Fe} 1(\mathrm{CFCl}, \mathrm{FeCl})$ & $\mathrm{YAl}_{0.96} \mathrm{Cr}_{0.03} \mathrm{Fe}_{0.01} \mathrm{O}_{3}$ \\
$\mathrm{Fe} 2$ & $\mathrm{YAl}_{0.96} \mathrm{Cr}_{0.02} \mathrm{Fe}_{0.02} \mathrm{O}_{3}$ \\
$\mathrm{Fe} 3$ & $\mathrm{YAl}_{0.96} \mathrm{Cr}_{0.01} \mathrm{Fe}_{0.03} \mathrm{O}_{3}$ \\
$\mathrm{Fe} 4$ & $\mathrm{YAl}_{0.96} \mathrm{Fe}_{0.04} \mathrm{O}_{3}$ \\
\hline
\end{tabular}

위해 광화제를 $6 \mathrm{wt} \%$ 첨가 하였다. ${ }^{10)}$ 또한 발색제로 사용 된 산화크롬 대신 반응성이 좋은 염화물을 사용하였을 경 우의 영향은 어떤지 알아보기 위해 염화물에 대한 일부 실험을 Table 1에서의 조합 $\mathrm{Cr}$ 4와 산화철이 사용되는 $\mathrm{Fe} 1$ 에 적용하여 염화물의 발색 영향을 실험하였다. 칭량된 원료는 마노 유발에서 에틸 알콜을 넣어 고르게 섞어 건 조시킨 후 도가니에 넣어 뚜껑을 덮은 후 $1450^{\circ} \mathrm{C}$ 의 온도 에서 소성하였으며, 각각 최고 온도에서 6시간 유지시킨 후 자연 냉각하였다. 승온 조건은 $900^{\circ} \mathrm{C}$ 까지는 $5^{\circ} \mathrm{C} / \mathrm{min}$, 최고온도까지는 $3^{\circ} \mathrm{C} / \mathrm{min}$ 이었다.

\section{2. 안료의 특성분석}

소성된 안료의 특성은 X-선 회절분석(X-ray Diffratometer, XRD-7000, Shimadzu, Japan), FT-IR(IRPrestige21(Shimadzu, Japan), Raman spectroscopy(Dimension-P2 Raman), SEM (scanning eletron microscopy, SS-550, Shimadzu, Japan), UV-vis spectrophotometer (2401-PC, Shimadzu, Japan)를 이용하여 분석하였다.

\section{3. 유약 적용 실험}

합성된 안료의 발색실험을 위해 합성안료에 미디엄을 섞어 초벌된 시험편에 바른 후에 $4 \times 4 \mathrm{~cm}$ 백자시험편에 석회유(Seger formular로 표시)를 시유하였다. 시유된 시험 편은 전기 가마 (siliconite furnace)에서 $1260^{\circ} \mathrm{C}$ 로 30 분 소 성한 뒤 노냉 하였다. 소성 조건은 $900^{\circ} \mathrm{C}$ 까지는 $5^{\circ} \mathrm{C} / \mathrm{min}$, $900 \sim 1260^{\circ} \mathrm{C}$ 까지는 $3^{\circ} \mathrm{C} / \mathrm{min}$ 로 하였다. 사용된 유약의 Seger formular는 다음과 같다.

$\begin{array}{llll}\text { lime-glaze } & & & \\ 0.3264 \mathrm{KNaO} & 0.4040 \mathrm{Al}_{2} \mathrm{O}_{3} & 3.5526 \mathrm{SiO}_{2} \\ 0.6588 \mathrm{CaO} & 0.0019 \mathrm{Fe}_{2} \mathrm{O}_{3} & \\ 0.0148 \mathrm{MgO} & & & \end{array}$

\section{4. 색상분석}

합성된 안료의 색상과 합성 안료를 사용해 소성한 시 험편의 유색상은 UV-vis spectrometer(2401-PC, Shimadzu, Japan)로 측정하여 먼셀(Muncell) 색 표시인 색상(H:hue), 명도(V : value), 채도(C:chroma)로 나타내었으며, 국제조 명위원회(CIE:Commission Internationale de l'Eclairage) 가 추천하는 CIE-L $\mathrm{a}^{*} \mathrm{~b}^{*}$ 표색계의 값을 사용하여 나타내 었다.

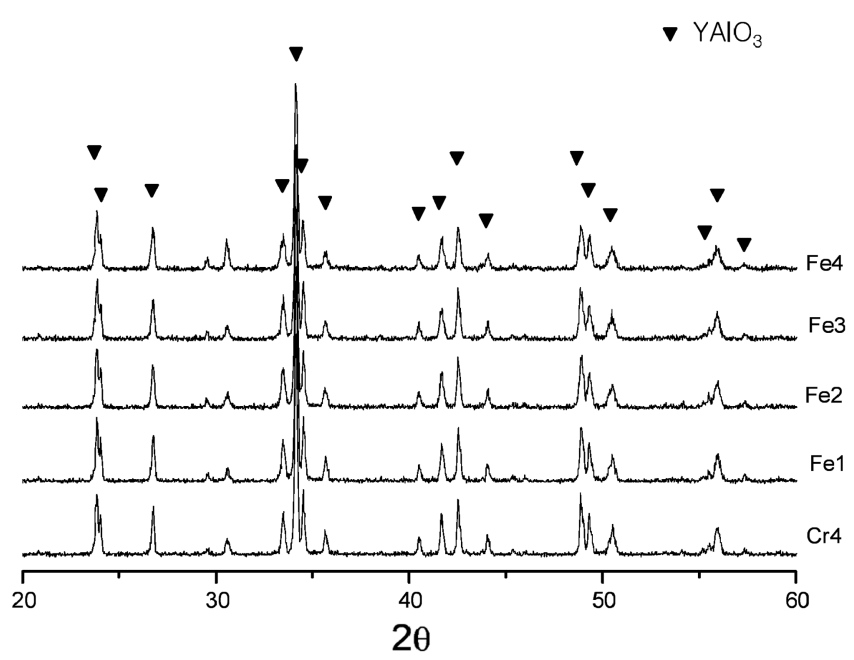

Fig. 1. X-ray diffraction patterns of samples obtained on calcining in air for $6 \mathrm{~h}$ at $1450^{\circ} \mathrm{C}$.

\section{3. 결과 및 고찰}

\section{1. $\mathrm{XRD}$ 분석}

소성된 안료의 결정상은 $\mathrm{X}$-선 회절분석을 이용하여 확 인하였다. 안료합성에 사용한 발색제 크롬을 철로 대체하 였을 때의 XRD 측정 결과는 발색제를 크롬만 사용하였 을 경우와 비슷한 결과를 나타내고 있다. 이는 크롬과 철 이 동일 주기에 속한 금속으로 철의 이온반경(0.64 А, 6 배위)과 크롬의 이온반경(0.69 $\AA, 6$ 배위 $)$ 이 비슷하기 때 문으로 생각된다.

\subsection{FT-IR 및 Raman 분석}

FT-IR 및 Raman 분석을 하였다. FT-IR은 reflectance mode이며 resolution은 $16 \mathrm{~cm}^{-1}$ 로 하였다. 발색제로 사용된 크롬을 철로 치환하여 소성한 안료의 FT-IR 및 Raman spectra를 Figs. 2 4에 나타내었다. 발색제로 산화크롬만을 사용한 안료 $\mathrm{Cr} 4$ 와 산화철만을 사용한 안료 $\mathrm{Fe} 4$ 를 비교 해보면 철의 특성 흡수밴드는 ${ }^{6)} 325 \mathrm{~cm}^{-1}, 468 \mathrm{~cm}^{-1}$ 과 $560 \mathrm{~cm}^{-1}$ 에서 강한 피크가 나타나는데 F4의 경우 Fig. 2(a) 에서 철의 피크가 $316.33 \mathrm{~cm}^{-1}$ 에서 나타나고 있다. 크롬의 특성밴드는 ${ }^{6} 555 \mathrm{~cm}^{-1}$ 과 $625 \mathrm{~cm}^{-1}$ 에서 강하게 나타나고 $435 \mathrm{~cm}^{-1}$ 와 $407 \mathrm{~cm}^{-1}$ 에서 약하게 나타나는데 $\mathrm{Cr} 4$ 의 경우 Fig. 2(a)에서는 $\mathrm{YAlO}_{3}$ 의 특성피크 ${ }^{7}$ 가 나타나는 408.9, $470.6,524.6,507.9,648.0 \mathrm{~cm}^{-1}$ 의 피크에 잘 고용되어 크롬 의 특성피크는 보이지 않는다. 이것은 Fig. 2(b)에서 370 $700 \mathrm{~cm}^{-1}$ 로 나타나고 있다.

발색제로 산화물대신 염화물을 사용했을 때 합성된 안 료의 결정은 XRD 분석으로는 산화물을 사용했을 때와 구분하기 힘들었다. 그러나 FT-IR이나 Raman 분석을 통 해서는 강도 세기의 차이를 통해 염화물을 사용했을 경우 


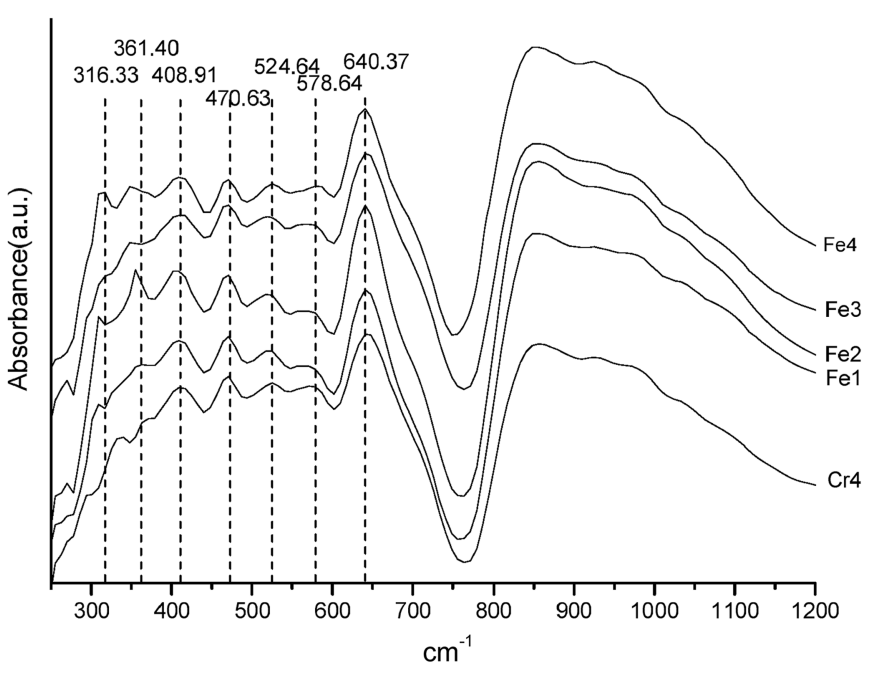

(a)

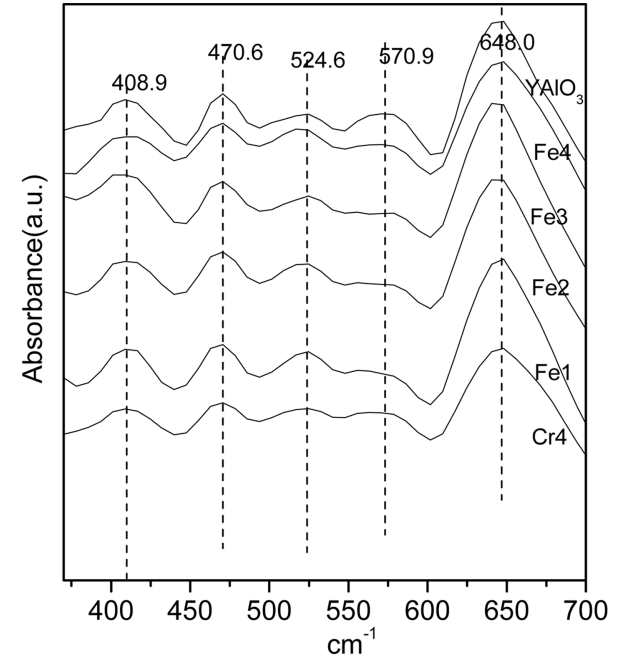

(b)

Fig. 2. FT-IR spectra of (a) samples fired at $1450^{\circ} \mathrm{C}$ and (b) $\mathrm{YAlO}_{3}$ and Samples at $370 \sim 700 \mathrm{~cm}^{-1}$.

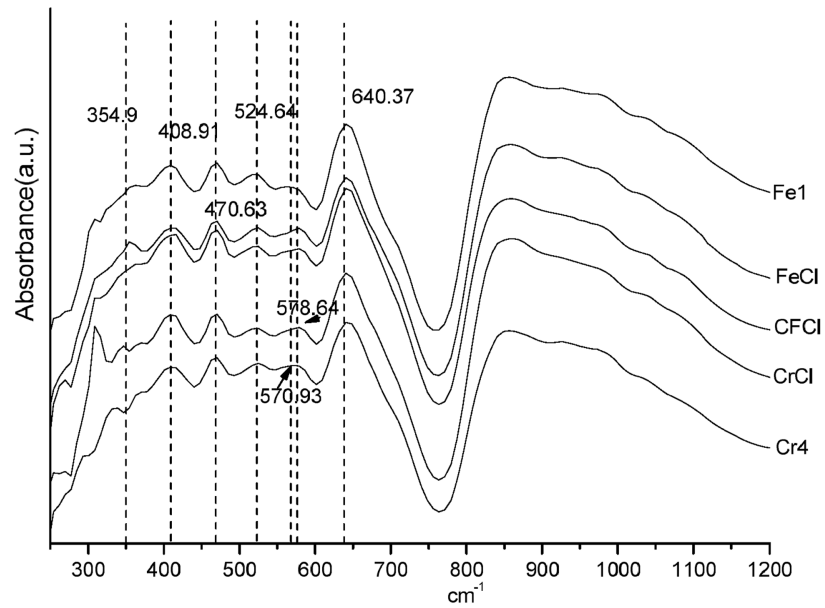

(a)

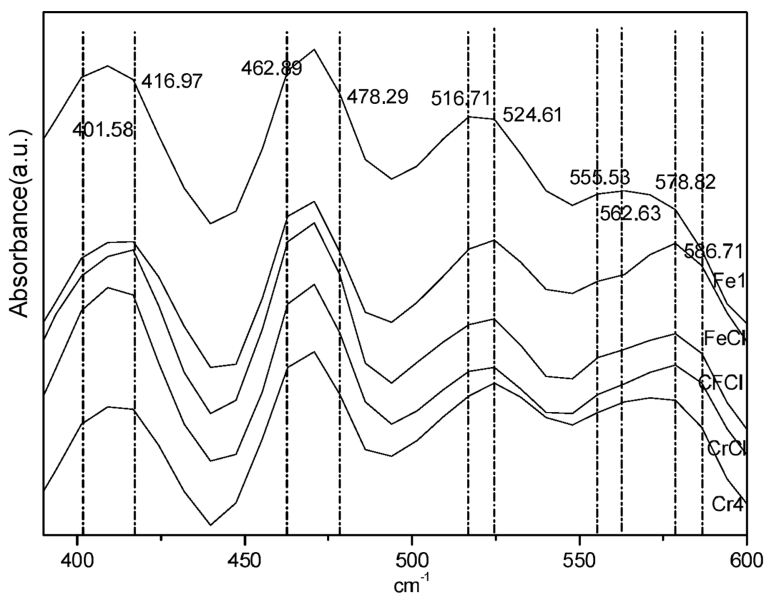

(b)

Fig. 3. FT-IR spectra of (a) samples used with chromium chloride and iron chloride fired at $1450^{\circ} \mathrm{C}$ and (b) enlarged area $390 \sim 600 \mathrm{~cm}^{-1}$.

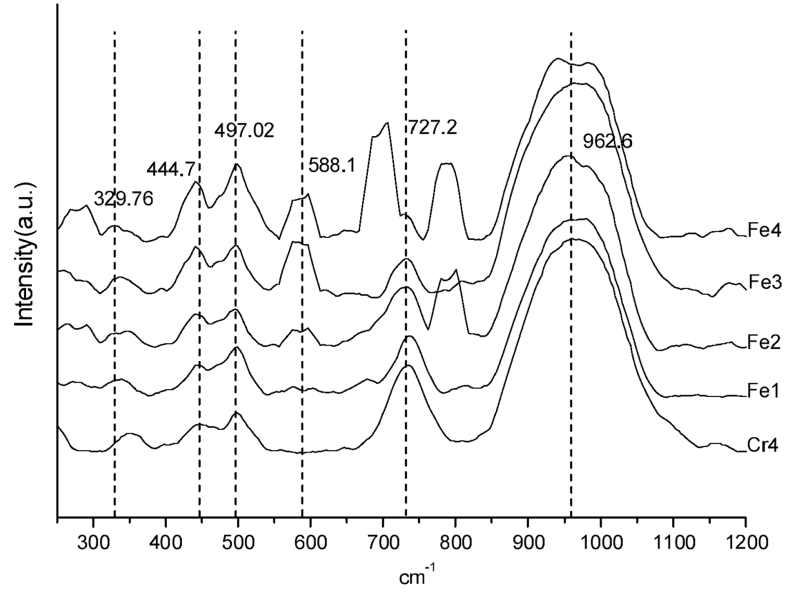

(a)

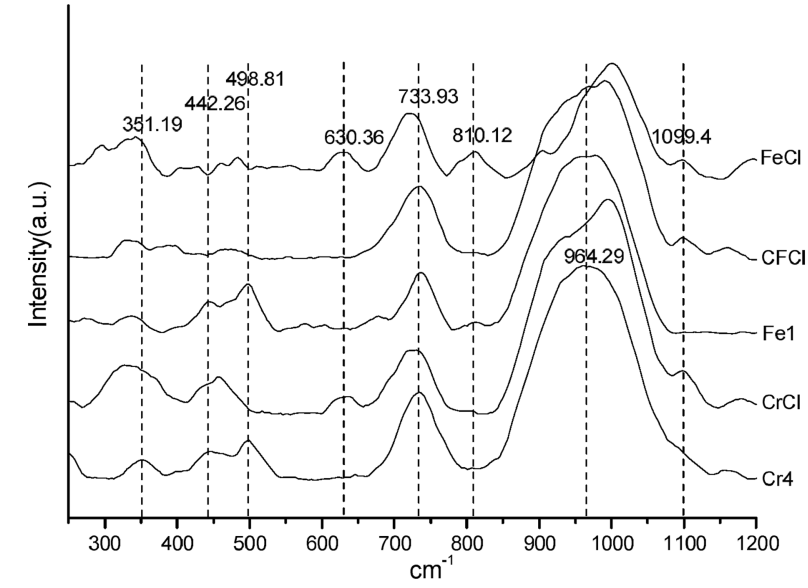

(b)

Fig. 4. Raman spectra of samples used (a)oxides and (b)chlorides fired at $1450^{\circ} \mathrm{C}$. 


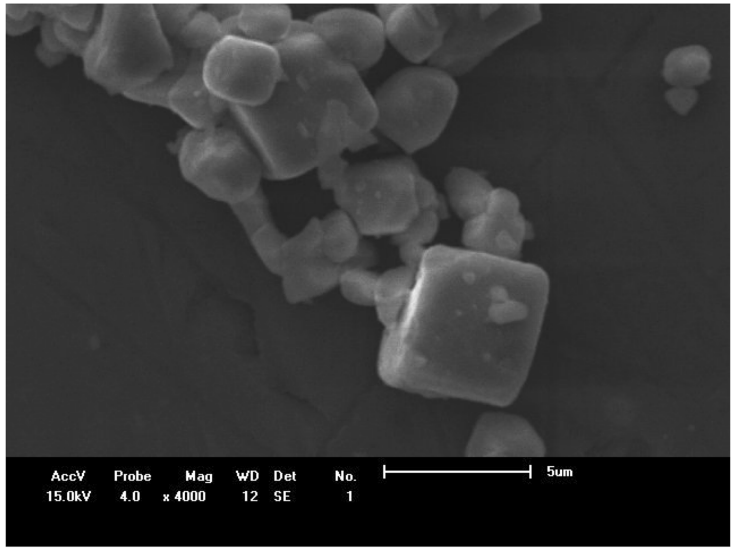

(a) $\mathrm{Cr} 4$

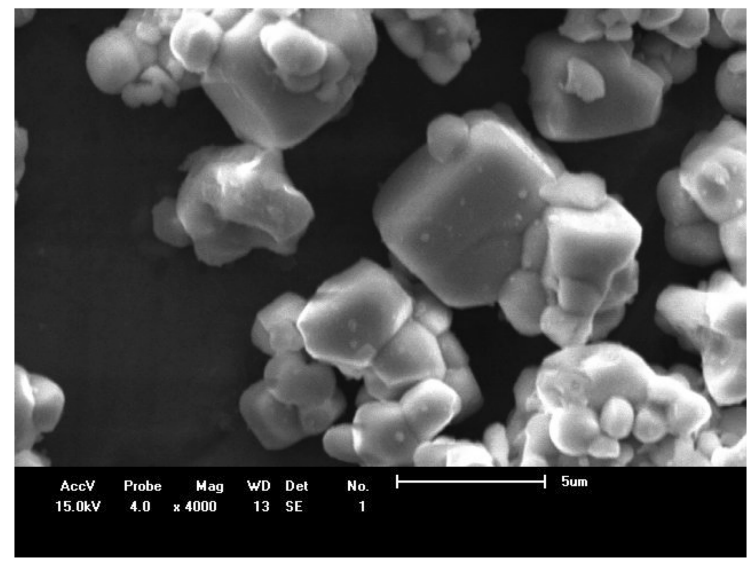

(c) $\mathrm{CrCl}$

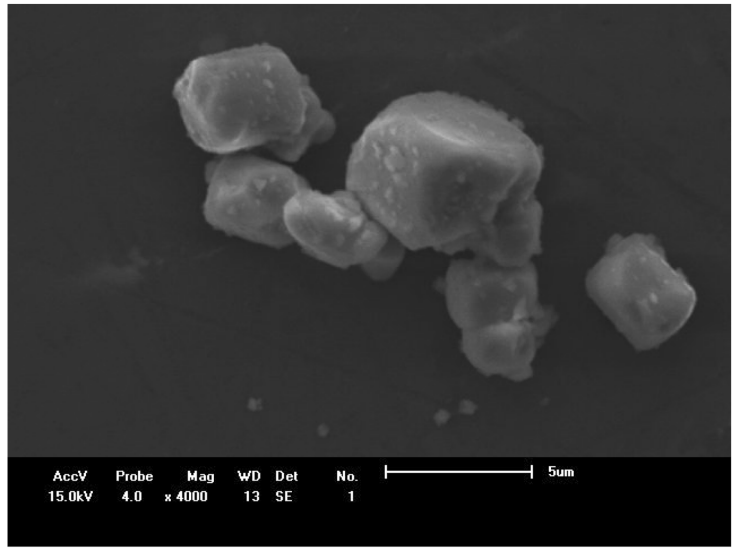

(b) Fel

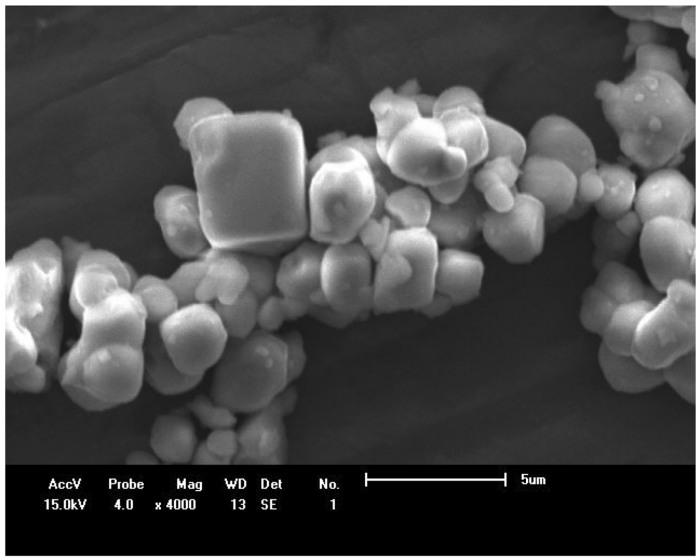

(d) $\mathrm{CFCl}$

Fig. 5. SEM micrographs of samples fired at $1450^{\circ} \mathrm{C}$ (a) $\mathrm{Cr}_{2} \mathrm{O}_{3}$, (b) $\mathrm{Cr}_{2} \mathrm{O}_{3}: \mathrm{Fe}_{2} \mathrm{O}_{3}(3: 1)$, (c) $\mathrm{CrCl}_{3} \cdot 6 \mathrm{H}_{2} \mathrm{O}$, and (d) $\mathrm{CrCl}_{3} \cdot 6 \mathrm{H}_{2} \mathrm{O}: \mathrm{FeCl}_{3} \cdot 6 \mathrm{H}_{2} \mathrm{O}(3: 1)$ used as chromophores.

더 반응성이 좋다는 것을 확인할 수 있었다(Fig. 3, Fig. 4). 산화물을 사용한 $\mathrm{Cr} 4$ 의 경우와 염화물을 사용한 $\mathrm{CrCl}$ 의 차이이다. $\mathrm{Fe} 1$ 과 $\mathrm{CFCl}$ 의 경우도 마찬가지이다. $\mathrm{FeCl}$ 의 경 우는 철은 산화물을 사용하고 크롬만 염화물을 사용한 경우 인데 두 가지를 모두 염화물로 사용한 것보다 $578.82 \mathrm{~cm}^{-1}$ 에 서 더 높은 피크를 보였고(Fig. 3(b)) 유약에서 더 붉게 발 색하였다.

Raman 분석에서는 FT-IR에서 미약하게 보였던 차이가 확연하게 보였다. Fig. 4(a)에서 $\mathrm{Fe} 4$ 의 경우 $329.76 \mathrm{~cm}^{-1}$ 와 $588.1 \mathrm{~cm}^{-1}$ 에서 철의 함량 증가에 따른 특성 밴드가 나타 났다. 염화물을 사용한 Fig. 4(b)의 경우에는 $964.29 \mathrm{~cm}^{-1}$ 에서 비대칭이 되고 $1099.4 \mathrm{~cm}^{-1}$ 에서 새로운 밴드가 나타났 다. 또한 산화물에서 나타난 밴드인 $440 \mathrm{~cm}^{-1}$ 과 $500 \mathrm{~cm}^{-1}$ 부 근의 밴드가 염화물을 사용하면 그 사이로 모아진다. 이 것은 천이금속의 양이온을 둘러싼 음이온과의 결합력에 의해 변하는데 산화물보다 결합력이 약한 염화물의 사용 으로 분열된 에너지차를 나타내는 $10 \mathrm{Dq}$ 의 값이 낮아짐 을 나타낸다. ${ }^{14)}$

\subsection{SEM}

합성된 안료의 미세구조는 Fig. 5와 같다. 입형은 육면체 형과 입자 성장에 의한 구형이 나타나고 있다. 발색제로 크롬만을 사용한 Fig. 5(a)와 크롬과 철을 사용한 Fig. 5(b) 를 보면 같은 육면체 형을 보여준다. 발색원료로 사용한 물질이 산화물이 아닌 염화물로 바꾸었을 경우도 같은 형 태를 나타내었다.

\subsection{UV-Vis spectra 분석}

합성된 안료의 UV-vis spectra를 Fig. 6에 나타내고, 안 료를 하회로 사용하여 석회유를 시유하여 소성한 결과의 UV-vis spectra를 Fig. 7에 나타내었다. 보통 크롬이 고용 된 물질의 색상은 크롬(III)에 적용된 결정장 이론에 의해 설명된다. R. S. Pavlov et al. 등 ${ }^{4)}$ 에 의하면 그것은 $\mathrm{d}^{3}$ 전 자 배열을 하고 산화물에서 팔면체 배위를 선호하고 몇 가지 전자 전이가 가능하다(Table 2)고 하였다. Y, U, R과 $\mathrm{R}^{\prime}$ 밴드는 가시광 영역에서 나타나고 이들의 위치와 형태 가 색상에 중요한 역할을 한다. 대부분의 팔면체 위치나 


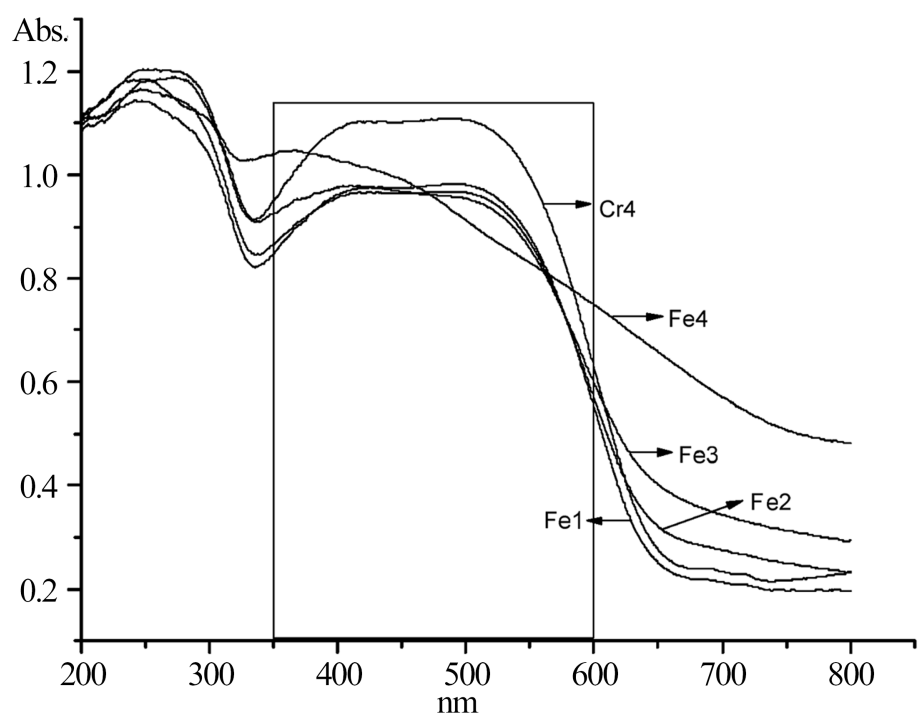

(a)

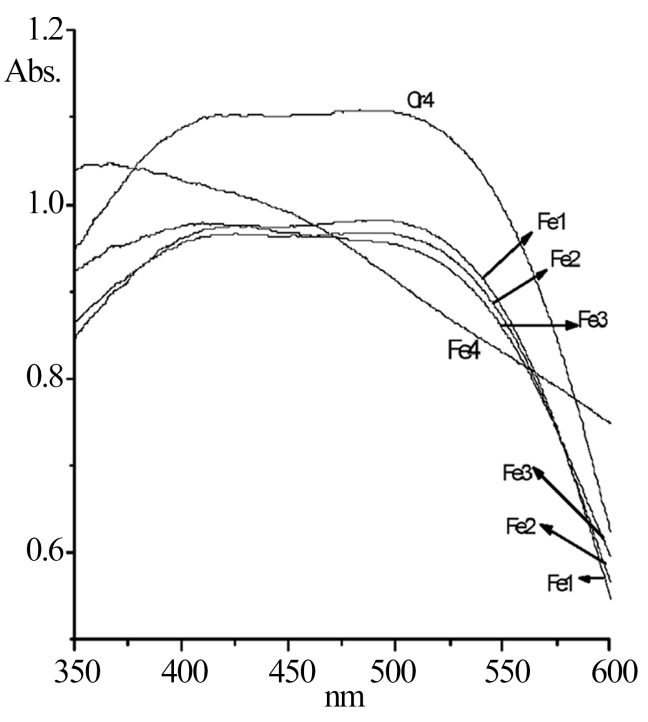

(b)

Fig. 6. UV-vis spectra of (a) samples fired at $1450^{\circ} \mathrm{C}$ and (b) enlaged area $350 \sim 600 \mathrm{~nm}$.

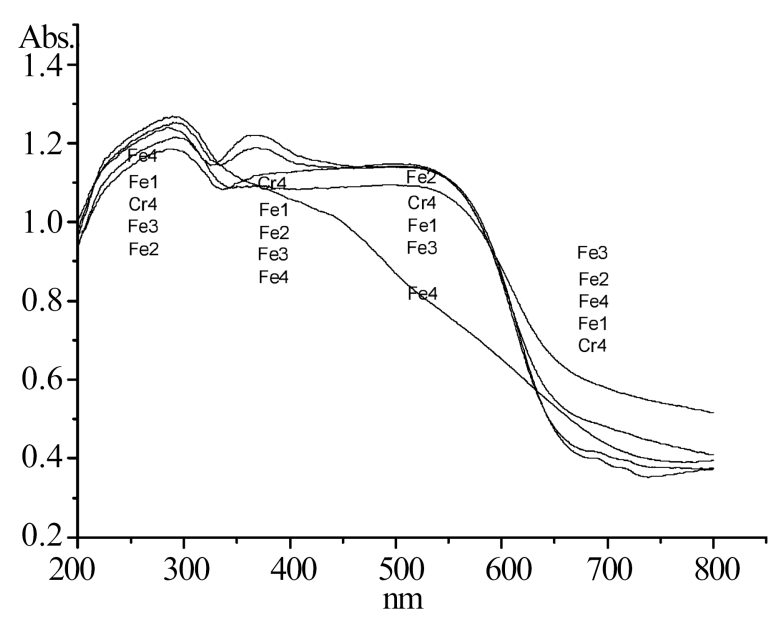

(a)

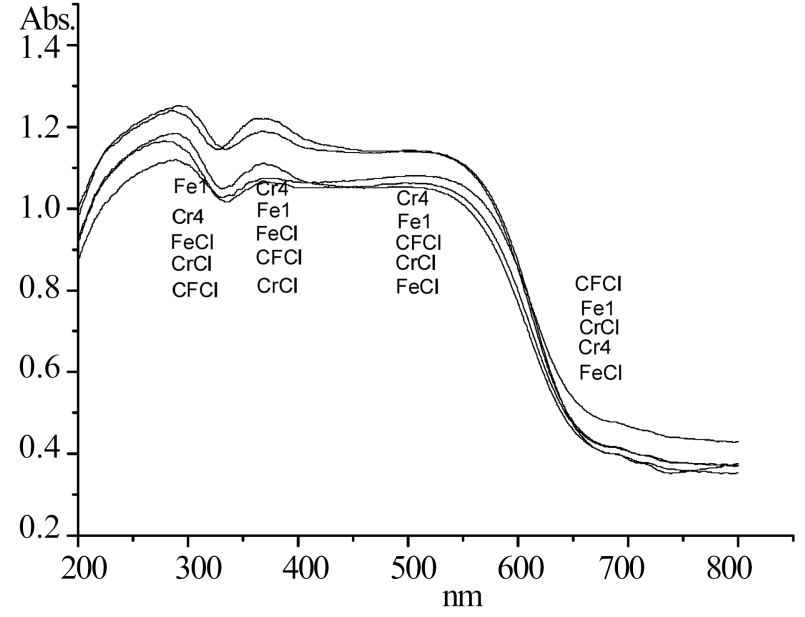

(b)

Fig. 7. UV-vis spectra of under-glazed tiles with samples fired at $1260^{\circ} \mathrm{C}$, (a) oxides (b) oxides and chlorides.

Table 2. Transitions of Cr(III) in Octahedral Crystal Field and Labels used for their Corresponding Bands

\begin{tabular}{cc}
\hline Transition & Band \\
\hline${ }^{4} \mathrm{~A}_{2 \mathrm{~g}} \rightarrow{ }^{2} \mathrm{E}_{\mathrm{g}}\left({ }^{2} \mathrm{G}\right)$ & $\mathrm{R}$ \\
${ }^{4} \mathrm{~A}_{2 \mathrm{~g}} \rightarrow{ }^{2} \mathrm{~T}_{1 \mathrm{~g}}\left({ }^{2} \mathrm{G}\right)$ & $\mathrm{R}^{\prime}$ \\
$\left.{ }^{4} \mathrm{~A}_{2 \mathrm{~g}} \rightarrow{ }^{4} \mathrm{~T}_{2 \mathrm{~g}}{ }^{4} \mathrm{~F}\right)$ & $\mathrm{U}$ \\
$\left.{ }^{4} \mathrm{~A}_{2 \mathrm{~g}} \rightarrow{ }^{2} \mathrm{~T}_{2 \mathrm{~g}}{ }^{2} \mathrm{G}\right)$ & $\mathrm{B}$ \\
$\left.{ }^{4} \mathrm{~A}_{2 \mathrm{~g}} \rightarrow{ }^{4} \mathrm{~T}_{1 \mathrm{~g}}{ }^{4} \mathrm{~F}\right)$ & $\mathrm{Y}$ \\
${ }^{4} \mathrm{~A}_{2 \mathrm{~g}} \rightarrow{ }^{4} \mathrm{~T}_{1 \mathrm{~g}}\left({ }^{4} \mathrm{P}\right)$ & $\mathrm{Y}^{\prime}$ \\
\hline
\end{tabular}

사면체 위치의 대칭은 입방체에서 벗어나 있는데 ${ }^{4,11-13)}$ 이 들의 편차는 발색단으로 작용하는 이온들의 결정장에서 의 에너지 수준 차이에 의한 분지 결과 $(10 \mathrm{Dq})$ 로 인한 흡
수밴드와 일치한다. 이들 원인에 따라 발색은 다양하게 나타난다. 즉 크롬이 고용되는 물질에서는 크롬이 어떤 원자가로 작용하는지, 또 그에 따른 구조적 불규칙에 의 한 대칭성이 발색을 좌우하게 된다. 크롬에 의한 붉은 색의 발색은 페로브스카이트 형에서는 팔면체 환경에서 크롬(III)이온에 대한 ligand field theory는 전자 전이에 의 한 3 개의 흡수 밴드를 갖는데 ${ }^{4,8,9)}$ 두개의 $\mathrm{p}$ 전자스핀은 가 시광 에너지와 일치하는 ${ }^{4} \mathrm{~A}_{2 \mathrm{~g}} \rightarrow{ }^{4} \mathrm{~T}_{1 \mathrm{~g}}(\mathrm{~F})$ 와 ${ }^{4} \mathrm{~A}_{2 \mathrm{~g}} \rightarrow{ }^{4} \mathrm{~T}_{2 \mathrm{~g}}(\mathrm{~F})$ 전이로 발색과 관련이 있고, 다른 한 개의 스핀은 ${ }^{4} \mathrm{~A}_{2 \mathrm{~g}} \rightarrow$ ${ }^{4} \mathrm{~T}_{1 \mathrm{~g}}(\mathrm{P})$ 전이로 자외선광과 일치하는 에너지로 발색에 영 향을 미치지 않는다. 이들은 산화물이온에 의해 형성되는 ligand field에 따라 밴드의 위치가 변경되고 이에 따라 다 양한 색이 나타나는 것이다. 순수한 $\mathrm{Cr}_{2} \mathrm{O}_{3}$ 의 흡수밴드는 
Table 3. Chromatic Coordinates of Synthesized Pigments

\begin{tabular}{ccccc}
\hline & $\mathrm{L}^{*}$ & $\mathrm{a}^{*}$ & $\mathrm{~b}^{*}$ & $(\mathrm{H})(\mathrm{V}) /(\mathrm{C})$ \\
\hline $\mathrm{Cr} 4$ & 45.48 & 31.56 & 21.18 & $7.3 \mathrm{R} 4.4 / 7.5$ \\
$\mathrm{Fe} 1$ & 50.12 & 29.39 & 19.91 & $7.2 \mathrm{R} 4.9 / 7.1$ \\
$\mathrm{Fe} 2$ & 49.35 & 25.81 & 18.44 & $7.8 \mathrm{R} 4.8 / 6.3$ \\
$\mathrm{Fe} 3$ & 48.72 & 20.49 & 16.77 & $9.0 \mathrm{R} \mathrm{4.7/5.1}$ \\
$\mathrm{Fe} 4$ & 45.92 & 4.48 & 13.01 & $8.5 \mathrm{YR} \mathrm{4.4/2.2}$ \\
$\mathrm{CrCl}$ & 47.93 & 33.96 & 23.63 & $7.4 \mathrm{R} \mathrm{4.7/8.2}$ \\
$\mathrm{CFCl}$ & 47.28 & 30.61 & 21.37 & $7.5 \mathrm{R} \mathrm{4.6/7.4}$ \\
$\mathrm{FeCl}$ & 47.00 & 29.84 & 21.09 & $7.7 \mathrm{R} \mathrm{4.6/7.2}$ \\
\hline
\end{tabular}

$580 \mathrm{~nm}$ 와 $405 \mathrm{~nm}$ 에서 나타난다. ${ }^{9)}$ 본 실험에서 크롬만을 사용한 경우에는 $415 \mathrm{~nm}$ 와 $510 \mathrm{~nm}$ 부근에서 넓게 나타났 다. 이것은 결정구조내에서 $\mathrm{Cr}(\mathrm{III})$ 에 의한 $\mathrm{Al}(\mathrm{III})$ 의 치환 에 의한 $\mathrm{Cr}-\mathrm{O}$ 거리 감소( $\mathrm{Al}(\mathrm{III})$ 의 이온반경 $0.51 \AA, \mathrm{Cr}(\mathrm{III})$ 의 이온 반경 $0.69 \AA)$ 에 의한 ligand field의 강도가 증가 한 때문이다. Visible spectrum의 green-blue violet 영역에 서의 강한 흡수 밴드는 orthorhombic perovskite에서 점대 칭의 낮아짐과 연관된 두개의 $\mathrm{Cr}^{3+}$ 피크의 유착에 의한 것 이며 페로브스카이트 안료의 붉은 색은 $350 \sim 650 \mathrm{~nm}$ 영 역에서의 강한 흡수 밴드에 의한 것이다. ${ }^{9)}$ 그런데 크롬과 철을 함께 사용했을 경우에는 철과 크롬의 고용량의 변 화에 따라 이들 ligand field에 따른 밴드의 위치는 조정 된다.

페로브스카이트 구조를 가진 $\mathrm{Ba}_{1-\mathrm{x}} \mathrm{Sr}_{\mathrm{x}} \mathrm{TiO}_{3}(\mathrm{BST})$ 에 철이 고용된 경우 ${ }^{5)}$ 그 발색은 광학적 흡수 위치에 따라 결정 되었다. 다양한 철의 농도에 따라 다른 흡수를 보였으며 철이 고용되면서 결정구조를 바꾸지 않았다. 본 실험의 $\mathrm{SEM}$ 측정 결과로도 확인 되었다(Fig. 5). 철은 이온 반경 이 크롬에 비해 약간 작다(0.64 $\AA, 6$ 배위). 따라서 그런 차이가 발색을 결정하는 흡수밴드의 폭과 강도를 결정하 게 된다. 크롬과 철을 함께 사용한 본 실험 결과에서는 철의 양이 많아질수록 사각형안의 큰 피크 봉우리의 강 도 변화가 커진다. 즉 두개의 피크 중 왼쪽 피크가 높아
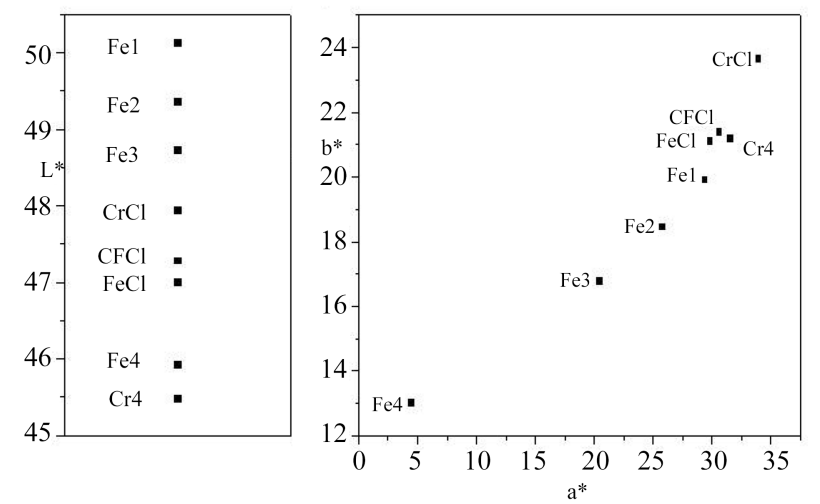

(a)
Table 4. Chromatic Coordinates of Underglazed Tiles with Lime-glaze

\begin{tabular}{ccccc}
\hline & $\mathrm{L}^{*}$ & $\mathrm{a}^{*}$ & $\mathrm{~b}^{*}$ & $(\mathrm{H})(\mathrm{V}) /(\mathrm{C})$ \\
\hline $\mathrm{Cr} 4$ & 42.00 & 27.65 & 14.76 & $5.5 \mathrm{R} 4.1 / 6.3$ \\
$\mathrm{Fe} 1$ & 37.93 & 21.08 & 11.02 & $5.8 \mathrm{R} 3.7 / 4.6$ \\
$\mathrm{Fe} 2$ & 40.62 & 22.38 & 12.38 & $6.1 \mathrm{R} \mathrm{3.9/5.0}$ \\
$\mathrm{Fe} 3$ & 36.96 & 14.74 & 7.88 & $6.2 \mathrm{R} \mathrm{3.6/3.1}$ \\
$\mathrm{Fe} 4$ & 44.57 & 6.13 & 14.99 & $7.8 \mathrm{YR} \mathrm{4.3/2.6}$ \\
$\mathrm{CrCl}$ & 41.25 & 20.78 & 10.40 & $5.2 \mathrm{R} \mathrm{4.0/4.6}$ \\
$\mathrm{CFCl}$ & 38.90 & 19.08 & 9.03 & $4.9 \mathrm{R} \mathrm{3.8/4.1}$ \\
$\mathrm{FeCl}$ & 41.02 & 21.66 & 11.88 & $6.0 \mathrm{R} \mathrm{4.0/4.9}$ \\
\hline
\end{tabular}

지고(blue-violet 흡수대) 오른쪽 피크(green 흡수대)는 낮 아졌다(Fig. 6(b)). 크롬을 완전히 철로 치환하였을 경우는 흡수대의 위치가 완전히 다르게 나타났고 색상은 붉은 색 이 아닌 갈색계통을 나타냈다(Fig. 7(a)).

\section{5. 색상 측정}

합성하여 분쇄한 안료를 미디엄과 섞어 시편에 바르고 미디엄이 건조된 상태에서 석회유를 시유하여 소성하였다. 색상은 UV-vis spectrometer(2401-PC, Shimadzu, Japan)로 측정하여 합성된 안료의 분말 색상과 유의 발색을 먼셀 (Muncell) 색 표시인 색상(H:hue), 명도(V:value), 채도 (C:chroma) 및 CIE-L ${ }^{*} \mathrm{a}^{*} \mathrm{~b}^{*}$ 표색계의 값 $\mathrm{L}^{*} \mathrm{a}^{*} \mathrm{~b}^{*}$ 로 Table 3 과 Table 4에 나타내었다.

합성된 안료(Fig. 8(a))를 하회로 사용하여 산화소성에서 소성한 결과를 Fig. 8(b)에 나타내었다. 크롬을 발색제로 사용하여 붉은 색을 얻을 수 있지만 철을 함께 사용해서 도 붉은 색을 얻을 수 있었다. 철만을 사용할 경우 붉은 색은 얻어지지 않고 철의 함량이 증가함에 따라 녹갈색 에서 검은 갈색으로 발색한다. 크롬과 철을 함께 사용하 여 합성된 안료는 환원 소성에서도 산화소성에서와 마찬 가지로 붉은 색을 발색하였다. 본 논문에서는 산화 소성 한 것만 제시하였다.
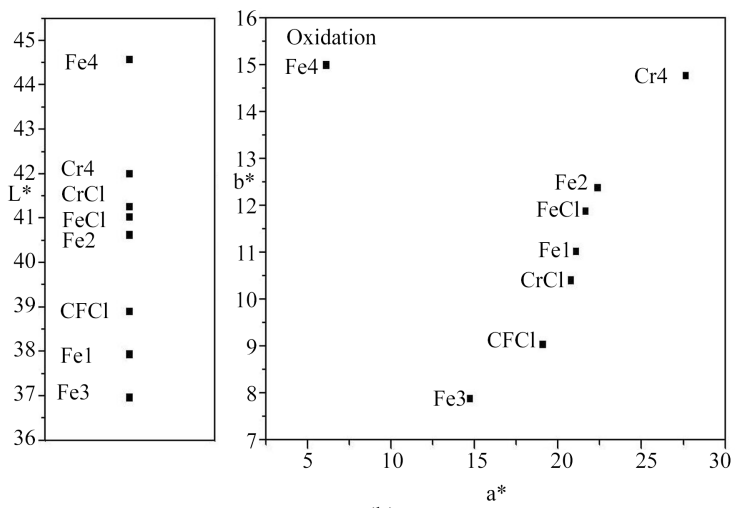

(b)

Fig. 8. Chromatic color coordinates of pigment powders(a) and glazed tiles(b) in the $\mathrm{L}^{*} \mathrm{a}^{*} \mathrm{~b}^{*}$ space. 


\section{4. 결 론}

$\mathrm{YAl}(\mathrm{Cr}) \mathrm{O}_{3}$ 조성의 붉은색 안료에서 크롬 사용에서 오는 환경적인 문제 야기를 예방할 수 있는 붉은 안료를 개발 하기 위해 발색제로 사용되는 크롬의 일부를 철로 대체 한 안료를 합성하였다.

$\mathrm{YAl}_{0.96}\left(\mathrm{Cr}_{0.04-\mathrm{x}} \mathrm{Fe}_{\mathrm{x}}\right) \mathrm{O}_{3}(\mathrm{x}=0.01,0.02,0.03,0.04)$ 의 실험결 과는 다음과 같이 요약된다.

1) 크롬만 사용하였을 경우 얻을 수 있는 붉은 색 $\left(\mathrm{L}^{*}:\right.$ $45.48, \mathrm{a}^{*}: 31.56, \mathrm{~b}^{*}: 21.18$ )은 철을 $0.01 \mathrm{~mole}$ 대체한 경우 각각 $50.12,29.39,19.91$ 이고 0.02 mole을 대체한 경우 $49.35,25.81,18.44$ 의 값을 나타냈다. 석회유약을 사용한 하회의 경우 크롬만 사용한 경우는 $\mathrm{L}^{*}: 42.00, \mathrm{a}^{*}: 27.65, \mathrm{~b}$ : 14.76 , 철을 0.01 mole 대체한 경우 각각 $37.93,21.08$, 11.02 이고 0.02 mole을 대체 한 경우 $40.62,22.38,12.38$ 의 값을 나타냈다.

크롬을 철로 대체하여 크롬과 철을 함께 사용할 경우 크롬을 0.02 mole까지 대체할 수 있다.

2) 철을 함께 사용해도 결정구조는 변하지 않으며, 발 색단으로 사용되는 원료를 산화물에서 염화물로 대체하 여 사용하는 경우도 $\mathrm{a}^{*}$ 값은 높게 나타났다.

\section{Acknowledgment}

이 논문은 2008년도 정부(과학기술부)의 재원으로 한국 과학재단의 지원을 받아 수행된 연구임(No.R0A-2006-00010442-0)

\section{REFERENCES}

1. M. Martos, M. Martnez, E. Cordoncillo, and P. Escribano, "Towards More Ecological Ceramic Pigments : Study of the Influence of Glass Composition on the Colour Stability of a Pink Chromium-doped Ceramic Pigment," J. Eur. Ceram. Soc., 27 4561-67 (2007).

2. K. H. Shin and B. H. Lee, "Synthesis of Cr-doped $\mathrm{Y}_{2} \mathrm{O}_{3}$ $\mathrm{Al}_{2} \mathrm{O}_{3}$ Red Pigments and their Application," J. Kor. Ceram.
Soc., 45 [8] 453-58 (2008).

3. E. Stobierska, J. Lis, M. M. Buko, and A. Gubernat, "Ceramic Pigments with Perovskite Structure," Advances in Science and Technology, 45 276-80 (2006).

4. Radostin S. Pavlov, V. B. Marzand, and J. B. Carda, "Electronic Absorption Spectroscopy and Colour of Chromiumdoped Solids," J. Mater. Chem., 12 2825-32 (2002).

5. Y. Zhu, D. Sun, Q. Huang, X. Jin, and H. Liu, "Uv-visible Spectra of Perovskite Iron-dopped $\mathrm{Ba}_{0.72} \mathrm{Sr}_{0.28} \mathrm{TiO}_{3}$," Material Letters, 62 407-9 (2008).

6. N. T. McDevitt and W. L. Baun, "Infrared Absorption Study of Metal Oxides in the Low Frequency Region $\left(700 \sim 240 \mathrm{~cm}^{-1}\right)$," Spectrochimica Acta, 20 799-808 (1964).

7. M. J. Weber, "Multiphonon Relaxation of Rare-earth Ions in Yttrium Orthoaluminate," Physical Review B, 8 [1] 54-64 (1973).

8. R. Galindo, M. Llusar, M. A. Tena, G. Monrs, and J. A. Badenes, "New Pink Ceramic Pigments Based on Chromium(IV)-doped Lutenium Gallium Garnet," J. Eur. Ceram. Soc., 27 199-205 (2007).

9. M. Martos, M. Marnetz, E. Cordoncillo, and P. Escribano, "Towards more Ecological Ceramin Pigments : Study of the Influence of Glass Composition on the Colour Stability of a Pink Chromium-doped Ceramic Pigment," J. Eur. Ceram. Soc., 27 4561-67 (2007).

10. M. Shirpour, M. A. Faghihi Sani, and A. Mirhabibi, "Synthsis and Study of a New Class of Red Pigments Based on Perovskite $\mathrm{YAlO}_{3}$ Structure," Cermics International, 33 [8] 1427-33 (2007).

11. S. R. Rotman, "Comment on : Optical and Electron Paramagnetic Resonance Studies of Fe Impurities in Yttrium Aluminum Garnet Crystals," Physical Review B, The American Physical Society, 41 [1] 791-92 (1990).

12. D. Dong, K. Xiao-Yu, G. Jian-Jun, W. Hui, and Z. KangWei, "Optical Absorption and EPR Study of the Octahedral $\mathrm{Fe}^{3+}$ Center in Yttrium Aluminum Garnet," Physical Review B, The American Physical Society, 72073101 (2005).

13. G. Lorenzi, G. Baldi, F. Di Benedetto, V. Faso, L. A. Pardi, and M. Romanelli, "HF ${ }^{2}$ EPR Investigation of a Cr-bearing Garnite Pigment," J. Euro. Ceram. Soc., 26 125-29 (2006).

14. W. D. Kingery, H. K. Bowen, and D. R. Uhlmann, Introduction to Ceramics; p. 680, Inc. 2nd, John Wiely \& Sons, 1976. 